www.jmscr.igmpublication.org

Index Copernicus Value: 79.54

ISSN (e)-2347-176x ISSN (p) 2455-0450

crossref DOI: https://dx.doi.org/10.18535/jmscr/v7i4.121

\title{
Geographic Tongue: Two Case Reports with Review
}

\author{
Authors \\ Dr M. Chandrasekhar, Dr Marisetty Charitha, Dr Ayesha Thabassum, \\ Dr G. Chandrasekhar, Dr Jyothirmayee \\ Department of Oral Medicine \& Radiology \\ Government Dental College, Kadapa, Andhra Pradesh, India
}

\begin{abstract}
Geographic tongue is a recurrent benign condition of tongue, which occurs in a diversity of age groups, and more prevalent in females than males. It is usually an asymptomatic condition, but some patients gives history of burning sensation, pain and during exacerbations submandibular lymphadenopathy. It has variable presentation in shape and size of lesions. Though it is a prevalent condition the definite etiology is not known. Usually considered as an oral manifestation of psoriasis, but definite results were not published till the date. This case report is to present the variable age groups and presenting symptoms and review about the possible etiology, associated factors and treatment of geographic tongue.

Keywords: Geographic tongue, Wandering rash, Erythema migrans, Cervical lymphadenopathy.
\end{abstract}

\section{Introduction}

Geographic tongue, or benign migratory glossitis, is usually an asymptomatic inflammatory disorder of the tongue mucosa of unknown etiology. It is characterized by circinate, erythematous, ulcerlike lesions of the dorsum and lateral border of the tongue due to loss of filiform papillae of the tongue epithelium. Lesions tend to change location, pattern, and size within minutes to hours. There have been many reports regarding the association between geographic tongue and psoriasis. $^{1,2}$ Here we describe two cases of geographic tongue in two different age groups with review of literature.

\section{Case Report 1}

A female patient aged 5 years came to the department of oral medicine and radiology with a chief complaint of white patches over front surface of tongue since one year, which were sudden in onset persists for one week and again reappears on other areas on tongue after 9-10 days. No history of burning sensation or any secondary discharges. Medical and dental history was non-contributory. On inspection four areas of depapillation are present on dorsal surface of tongue, measuring about $1.5 \mathrm{~cm} \times 1 \mathrm{~cm}$ in their maximum dimensions, which are oval to irregularly shaped, surrounded by white circinate borders (Figure 1). On palpation, there was no tenderness and the lesions are non-scrapable. Based on the history and clinical findings, diagnosis was given as benign migratory glossitis.

\section{Case Report 2}

A male patient aged 35 years came with a chief complaint of burning sensation on tongue since 2 years, which is moderate in intensity, aggravated 


\section{JMSCR Vol||07||Issue||04||Page 721-725||April}

to spicy foods and relieves on time, and patient gave history of white patches over tongue which are recurring in nature. Medical and dental history was non-contributory. Patient was a known smoker since one year and known alcoholic since 7 years. Intraorally on inspection there are three erythematous depapillated areas measuring $1.8 \times 1.5 \mathrm{~cm}$ in their maximum dimensions and lesions were covering almost entire left and right lateral surfaces, varying in shapes like oval, round and diffusely shaped surrounded by white border (Figure 2). No signs of any secondary changes. On palpation lesions were non-tender and nonscrapable. No signs of regional lymphadenopathy seen.

Figure 1(a) Profile and (b) Lesions on dorsal surface of tongue

(a)

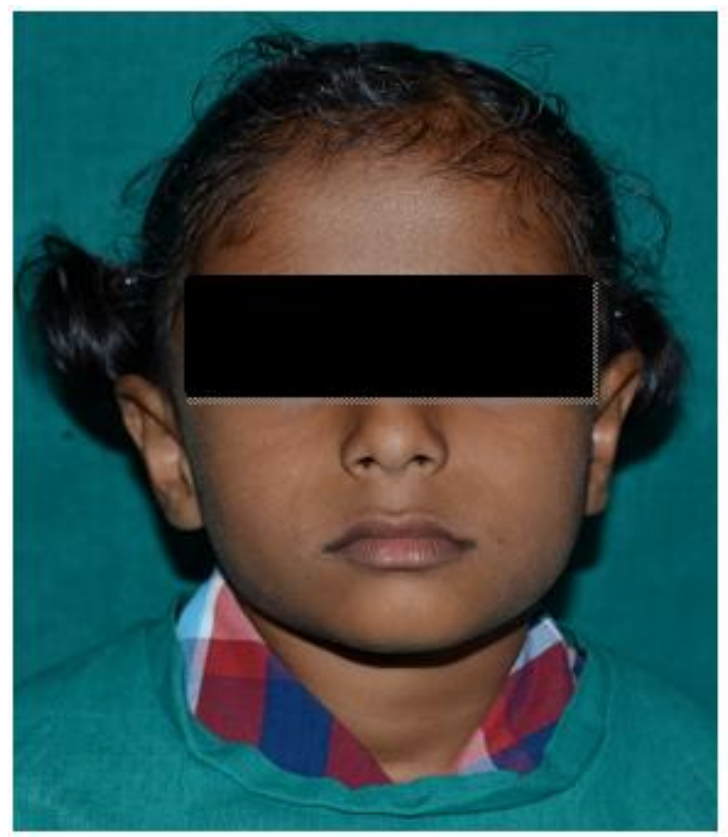

(b)

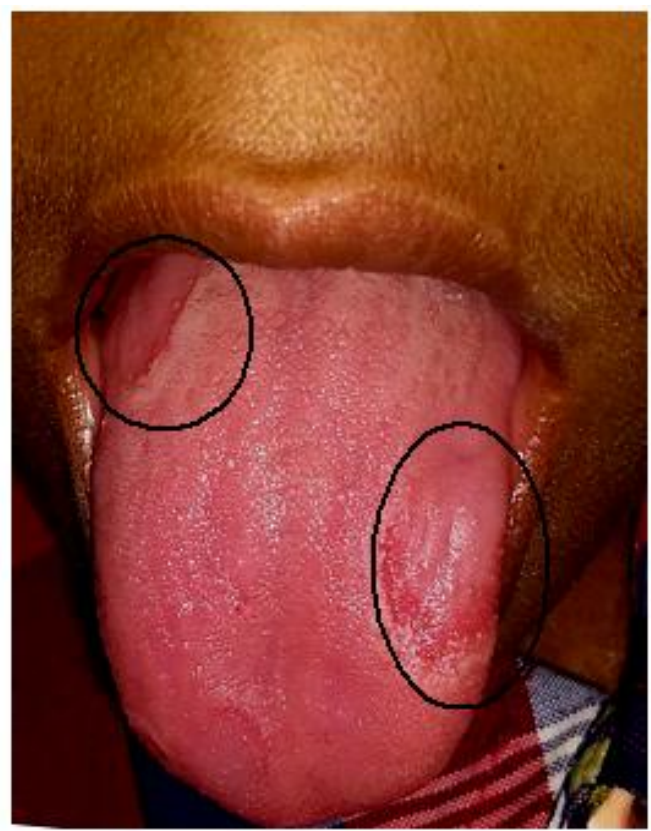

Figure 3: (a) Profile and lesions on (b)dorsal surface of tongue

(a)

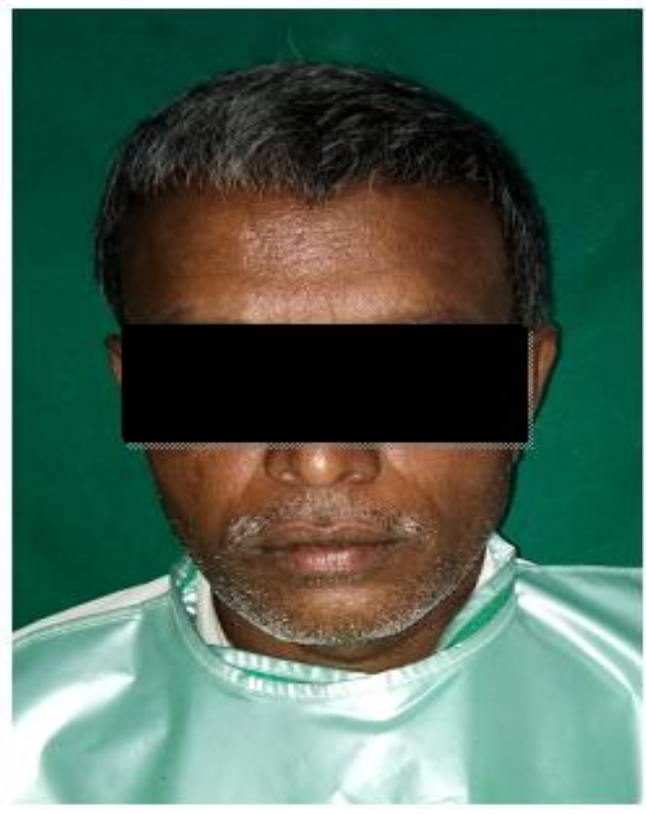

(b)

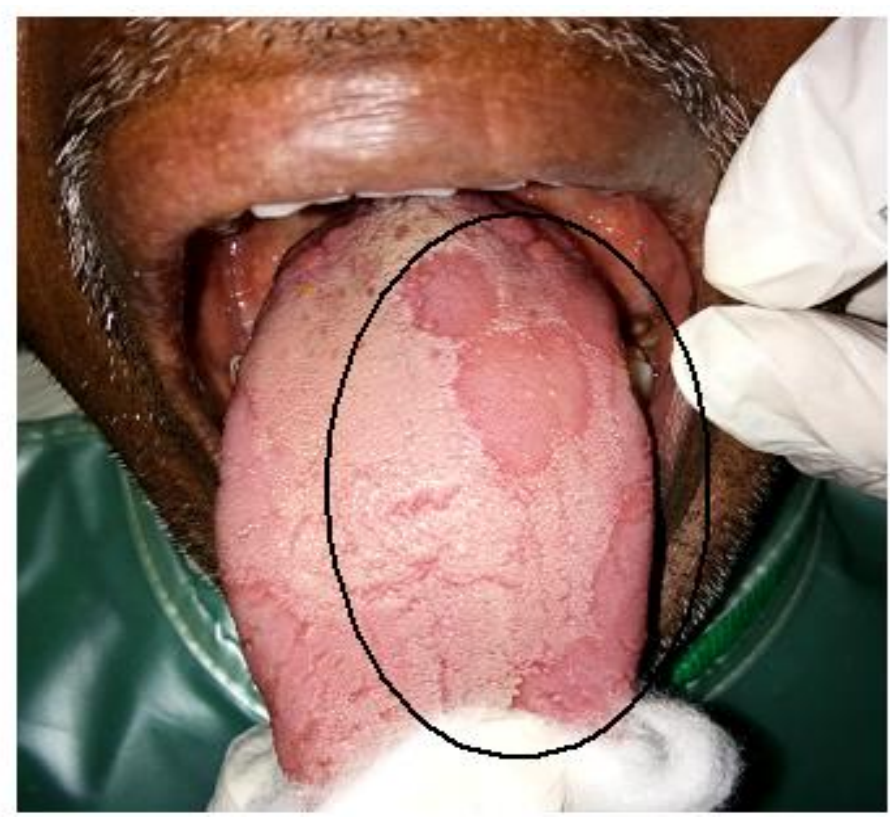


(c)

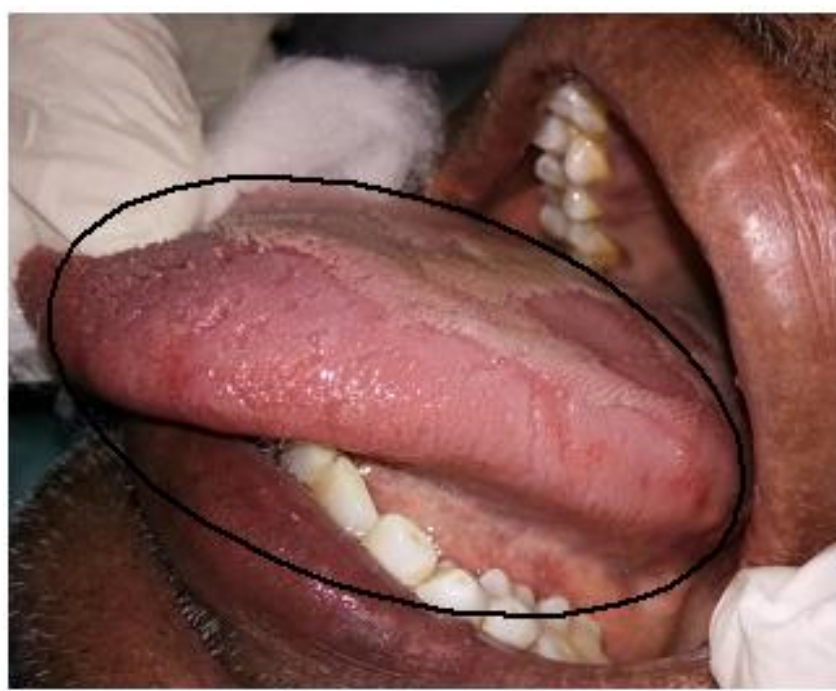

\section{Discussion}

Benign migratory glossitis is a recurrent condition of tongue of unknown etiology ${ }^{1}$. It was first described by Rayer as "wandering rash of the tongue" in $1831^{5}$. The lesions heal and frequently develop quickly in other areas, prompting the name of benign migratory glossitis Majority of the lesions are asymptomatic, but some cases show symptoms like pain, burning sensation, decreased taste sensation, sensing a foreign body or pain in the ear/ submandibular nodes ${ }^{1,2}$. It has a prevalence rate of about $3 \%$ in united states ${ }^{3}$; according to Patil. S et al. Prevalence of total tongue lesions in India is $12.07 \%$, of which geographic tongue constitutes $16.4 \%$ benign condition commonly seen on the tip, lateral borders and dorsum of the tongue.

According to analysis of Redman RS et al., the prevalence of this condition differs in no important respect according to age or sex, although there is possibility that it may be significantly greater among the very young ( 2 to 3 years of age $)^{8}$.

Many risk factors have been proposed for GT: hormonal disturbances and oral contraceptive use, psychological findings, diabetes mellitus, allergic conditions such as atopy, hay fever and rhinitis and dermatological diseases such as pustular Psoriasis, seborrheic dermatitis and, pityriasis rubra pilaris (Wysocki and Daley, 1987); and Reiter's Syndrome. There is also a reported (d)

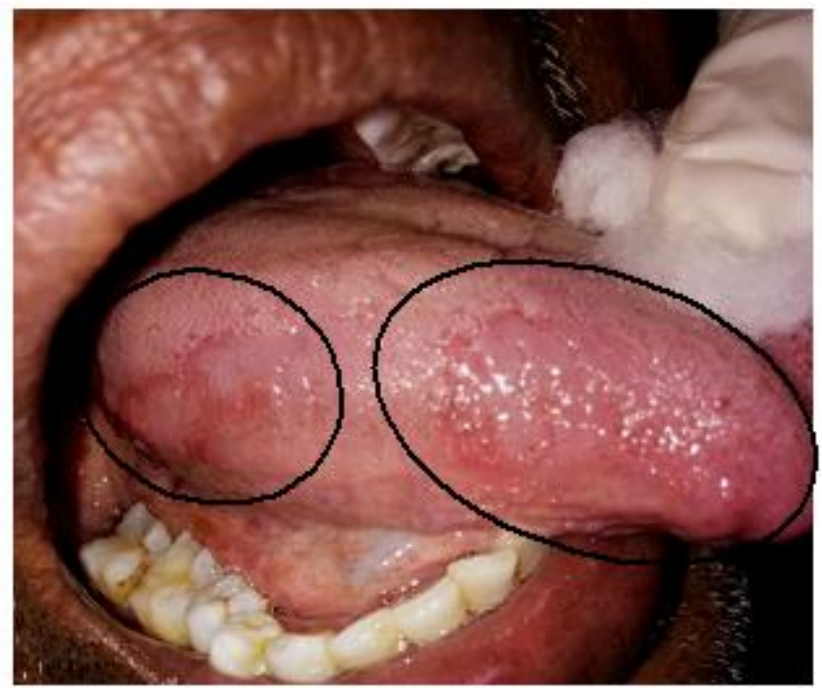

correlation with Down syndrome (Ercis et al, 1996) and fissured tongue (FT). Emotional stress is one of the factors in the development of this condition. ${ }^{12}$. Hubiche $\mathrm{T}$ et al., reported the occurrence of a geographic tongue in patients treated with some multitargeted kinase inhibitors humanized anti-VEGF (vascular endothelial growth factor) monoclonal antibody bevacizumab (Avastin, Roche) for patients as monotherapy for metastatic renal cell carcinoma. In a study conducted by Alikhani $\mathrm{M}$ et al. salivary level of IL-6 in GT was significantly higher.

Various Clinical Presentations: Geographic tongue varied clinically from small areas of loss of filiform papillae to florid widespread changes of edematous white areas surrounding denuded erythematosus patches. $^{11}$ Migratory welldemarcated areas with elevated yellowish hyperkeratotic borders, erythematous erosions, with loss of filiform papillae, surrounded by white circinate rims type lesions were reported by Hubiche T et al. ${ }^{17}$

Histological Presentation: Histologic lesions parallel the clinical appearance of the epithelium of the tongue. Histologic examination may reveal an acute and chronic inflammatory infiltrate in the submucosa, with epithelial edema and with neutrophils forming micro abscesses. The central erythematous patch represents atrophy of the filiform papillae, have mononuclear infiltrates in sub- and interepithelial positions, two types of 
basal cells (either typical epidermal basal cells or immature basal cells), filament and filament bundle formation in the spinous layer, lack of a stratum granulosum, and incomplete keratinization or parakeratinization in the surface layer. The white border is composed of regenerating filiform papillae and a mixture of keratin and neutrophils, leukocyte invasion into the epithelial layer, inter epithelial edema, rupture of cell junctions, glycogen deposits in epithelial cells, and exfoliation of necrotic cells in the surface layer ${ }^{5,9,16}$. Differentiation into filiform papillae is lacking in the erythematous areas. Scanning electron microscopy has revealed that the surface of geographic tongue contains two types of abnormal mucosa: an atrophic area, on which the hair of filiform papillae is absent but the bodies appear typical, and a white margin of desquamating cells. Microfissures are located between atrophic and normal mucosa. ${ }^{5}$

Associated Conditions: According to Rezaei $\mathrm{F}$ et al., study conducted in 7-18 years old students there was no association between psoriasis and geographic tongue, but as the study group was lower age the authors expected the psoriasis may manifest at an elder age ${ }^{7}$. Wysocky et al. stated that there is a relationship between geographic tongue and diabetes and found a fourfold increase in the prevalence of geographic ${ }^{9}$. As per the studies conducted by Jainkittivong A, et al. to determine the association between geographic tongue and scrotal tongue, in the age group of 1 to 60 years and above patients there was a higher concurrence of fissures with the typical appearance of a central atrophic area bounded by a raised circinate line showed a significant coexistence $^{9,13}$, and there is a genetic linkage between the two conditions in males ${ }^{22}$. Atopy is one of the conditions that manifests geographic pattern on tongue ${ }^{10}$ and it was found that HLA antigen B15 were raised in these patients ${ }^{11}$, but it is not exclusive to that disorder. It is more likely that it is a sign common to those patients who have a tendency to develop recurrent acute inflammatory diseases (asthma rhinitis) on surfaces in contact with the external environment, whether or not they are atopic. ${ }^{11}$ in children up to 2 years is the association between geographic tongue, seborrheic dermatitis, and spasmodic bronchitis was reported by rahamimoff et al.,

Diagnosis was mainly based on detailed history and clinical presentation.

Treatment: In asymptomatic case no treatment is required. Patient should be assured of the condition. Successful treatment with topical $0.1 \%$ tacrolimus for symptomatic geographic tongue was reported by Ishibashi $\mathrm{M}$ et al., ${ }^{14}$ Tacrolimus is an immunosuppressive macrolide and its antiinflammatory action is similar to that of cyclosporine, which involves the inhibition of interleukin 2 (IL-2) production by T cells.

\section{Conclusion}

In the present case reports two different age groups were determined which implies it has a wide range of age group and symptoms may or may not be present. More researches are needed to find out the exact etiology and factors associated for symptoms associated and non-symptomatic cases.

\section{References}

1. Kumar T, Puri G, Aravinda K, Arora N. Benign migratory glossitis: $\mathrm{A}$ rare presentation of a common disorder. Journal of Indian Academy of Oral Medicine and Radiology. 2015 Jan 1; 27(1):112.

2. Shulman JD, Carpenter WM. Prevalence and risk factors associated with geographic tongue among US adults. Oral diseases. 2006 Jul; 12(4):381-6.

3. Chaubal T, Bapat R. Geographic Tongue. The American journal of medicine. 2017 Dec 1;130(12):e533-4.

4. Shulman JD, Carpenter WM. Prevalence and risk factors associated with geographic tongue among US adults. Oral diseases. 2006 Jul;12(4):381-6.

5. Assimakopoulos D, Patrikakos G, Fotika C, Elisaf M. Benign migratory glossitis or 
geographic tongue: an enigmatic oral lesion. The American journal of medicine. 2002 Dec 15;113(9):751-5.

6. Shah N, Kariya P, Dave B, Thomas P. Geographic tongue: A case report with review of literature. Advances in Human Biology. 2016 Sep 1;6(3):142.

7. Rezaei F, Safarzadeh M, Mozafari H, Tavakoli P. Prevalence of geographic tongue and related predisposing factors in 718 year-old students in Kermanshah, Iran 2014. Global journal of health science. 2015 Sep;7(5):91.

8. Redman RS. Prevalence of geographic tongue, fissured tongue, median rhomboid glossitis, and hairy tongue among 3,611 Minnesota schoolchildren. Oral Surgery, Oral Medicine, Oral Pathology. 1970 Sep 1;30(3):390-5.

9. Jainkittivong A, Langlais RP. Geographic tongue: clinical characteristics of 188 cases. J contemp dent pract. 2005 Feb 15;6(1):12335.

10. MARKS R, SIMONS MJ. Geographic tongue - a manifestation of atopy. British Journal of Dermatology. 1979 Aug;101(2):159-62.

11. Marks R, Czarny D. Geographic tongue: sensitivity to the environment. Oral Surgery, Oral Medicine, Oral Pathology. 1984 Aug 1;58(2):156-9.

12. Redman RS, Vance FL, Gorlin RJ, Peagler FD, Meskin LH. Psychological component in the etiology of geographic tongue. Journal of dental research. 1966 Sep;45(5):1403-8.

13. Eidelman E, Chosack A, Cohen T. Scrotal tongue and geographic tongue: polygenic and associated traits. Oral Surgery, Oral Medicine, Oral Pathology. 1976 Nov 1;42(5):591-6.

14. Ishibashi M, Tojo G, Watanabe M, Tamabuchi T, Masu T, Aiba S. Geographic tongue treated with topical tacrolimus. Journal of dermatological case reports. 2010 Dec 31;4(4):57.

15. Rahamimoff P, Muhsam HV. Some Observations on 1246 Cases of Geographic Tongue: The Association between Geographic Tongue, Seborrheic Dermatitis, and Spasmodic Bronchitis-Transition of Geographic Tongue to Fissured Tongue. AMA journal of diseases of children. 1957 May 1;93(5):519-25.

16. Dawson TA. Microscopic appearance of geographic tongue. British Journal of Dermatology. 1969 Nov;81(11):827-8.

17. Hubiche T, Valenza B, Chevreau C, Fricain JC, Del Giudice P, Sibaud V. Geographic tongue induced by angiogenesis inhibitors. The oncologist. 2013 Apr 1;18(4):e16-7.

18. Alikhani M, Khalighinejad N, Ghalaiani P, Khaleghi MA, Askari E, Gorsky M. Immunologic and psychologic parameters associated with geographic tongue. Oral surgery, oral medicine, oral pathology and oral radiology. 2014 Jul 1;118(1):68-71.

19. Plackova A, Skach M. The ultrastructure of geographic tongue. Oral Surgery, Oral Medicine, Oral Pathology. 1975 Dec 1;40(6):760-8.

20. Patil S, Kaswan S, Rahman F, Doni B. Prevalence of tongue lesions in the Indian population. Journal of clinical and experimental dentistry. $2013 \mathrm{Jul} ; 5(3)$ :e128.

21. Najafi S, Gholizadeh N, Rezayat EA, Kharrazifard MJ. Treatment of symptomatic geographic tongue with triamcinolone acetonide alone and in combination with retinoic acid: a randomized clinical trial. Journal of dentistry (Tehran, Iran). 2016 Jan;13(1):23.

22. Ghose LJ, Baghdady VS. Prevalence of geographic tongue and plicated tongue in 6090 Iraqi schoolchildren. Community Dent Oral Epidemiol 1982; 10: 214-216. 